\title{
Electrical stimulation changes human mesenchymal stem cells orientation and cytoskeleton organization
}

DOI:

10.1166/jbt.2017.1631

\section{Document Version}

Accepted author manuscript

Link to publication record in Manchester Research Explorer

\section{Citation for published version (APA):}

Mobini, S., Talts, Ü-L., Xue, R., Cassidy, N. J., \& Cartmell, S. (2017). Electrical stimulation changes human mesenchymal stem cells orientation and cytoskeleton organization. Journal of Biomaterials and Tissue Engineering, 7(9), 829-33. https://doi.org/10.1166/jbt.2017.1631

\section{Published in:}

Journal of Biomaterials and Tissue Engineering

\section{Citing this paper}

Please note that where the full-text provided on Manchester Research Explorer is the Author Accepted Manuscript or Proof version this may differ from the final Published version. If citing, it is advised that you check and use the publisher's definitive version.

\section{General rights}

Copyright and moral rights for the publications made accessible in the Research Explorer are retained by the authors and/or other copyright owners and it is a condition of accessing publications that users recognise and abide by the legal requirements associated with these rights.

\section{Takedown policy}

If you believe that this document breaches copyright please refer to the University of Manchester's Takedown Procedures [http://man.ac.uk/04Y6Bo] or contact uml.scholarlycommunications@manchester.ac.uk providing relevant details, so we can investigate your claim.

\section{OPEN ACCESS}




\title{
Electrical stimulation changes human mesenchymal stem cells orientation and cytoskeleton organization
}

\author{
Sahba Mobini ${ }^{1}$, Ülle-Linda Talts ${ }^{* 1}$, Ruikang Xue ${ }^{1}$, Nigel J Cassidy ${ }^{2}$, Sarah H \\ Cartmell $^{* * 1}$ \\ ${ }^{1}$ School of Materials, The University of Manchester, Manchester, UK \\ ${ }^{2}$ School of Engineering, The University of Birmingham, Birmingham, UK \\ * Sahba Mobini and Ülle-Linda Talts contributed equally to this work \\ ** Corresponding Author
}

\begin{abstract}
Electricity, as a physical stimulus, is recently becoming an attractive tool for tissue engineering. In this study we simulated the electrical field delivered by a simplified electro-bioreactor, using finite element analysis. In addition, human mesenchymal stem cells (hMSCs) were cultured in an electro-bioreactor and an electrical field of $100 \mathrm{mV} / \mathrm{mm}$ for 1 hour per day was applied. The cell profile, orientation and cytoskeleton changes by CellProfiler was analysed at 1, 2, 3 and 7 days. The cytoskeleton texture of cells exposed to electrical stimulation was also compared with cells exposed to chemical stimulation during an early phase of osteogenic differentiation. Results showed that hMSCs orientation and cytoskeleton actin filaments reorganize perpendicular to the electrical field in the vicinity of the cathode area at day 7. This finding and analysis method has the potential to provide a framework for future studies of mechanism underlying the changes in cell profile in electrical fields.
\end{abstract}

Keywords: Electrical stimulation, Cell orientation, Computational modelling, Cytoskeleton reorganization 


\section{Introduction}

Tissue engineering is a growing area of science, combining cells and stimuli, to direct the cells to differentiate into the desired phenotype within a specific time (Grayson, Martens, Eng, Radisic, \& Vunjak-Novakovic, 2009). The concept of the endogenous electrical stimuli has been proven to be involved in important physiological processes such as endothelial tissue healing as well as complex tissue regeneration (Levin, 2009; Nuccitelli, 2003). Accordingly, exogenous electrical stimulation (ES) has been taken into account, as one of the efficient physical stimuli, which is able to increase the healing and/or regeneration capacity of the various tissues (McCaig, Song, \& Rajnicek, 2009). To have a better understanding of the function of ES and to optimize the conditions for tissue bioengineering and/or tissue regeneration, it is essential to study the changes in stem cell behaviours in presence and absence of the electrical field (Titushkin \& Cho, 2007). In vitro, electrical fields have been shown to influence the reorganisation of the cell membrane receptors (Griffin \& Bayat, 2011), as well as the cytoskeleton (Sun, Titushkin, \& Cho, 2006; Titushkin \& Cho, 2009). Hammrick et al. showed that mouse adipose-derived stromal cells dramatically reorganize their cytoskeleton in response to the ES and these morphological changes lead to changes in function (Hammerick, Longaker, \& Prinz, 2010; Kim et al., 2006). A cell's ability to adapt changes to cytoskeleton structure has been linked with differentiation commitment as shown in a study on mesenchymal stem cells and osteoblasts by Titushkin et al (Titushkin \& Cho, 2007, 2009). Several studies have recorded an increase in ostegeoblast lineage markers such as alkaline phosphatase and osteopontin in the stem cells that received daily electrical stimulation (Balint, Cassidy, HidalgoBastida, \& Cartmell, 2013; Mobini, Leppik, \& Barker, 2016).

According to the effective role of cytoskeleton organization in cell mechanics, stability and motility which is able to promote subsequent functions such as the differentiation rate, we have investigated the changes in cytoskeleton actin filaments organization and orientation of human mesenchymal stem cells (hMSCs), in response to $100 \mathrm{mV} / \mathrm{mm}$ directly applied DC ES and compared it to the responses of chemical stress, applied by exposing the cells to the osteogenic supplies. 


\section{Materials and Methods}

To apply ES to the cells, a simplified electro-bioreactor was utilized which was described previously (Mobini et al., 2016). Commercial finite-element analysis software, COMSOL Multiphysics ${ }^{\circledR}$ (version 5.1, COMSOL, UK) was used to model the electro-bioreactor and simulate the electrical field distribution. The detailed parameters are described in Table 1. Human mesenchymal stem cells from bone marrow obtained from (PT-2501, Lonza Group Ltd, Germany). Frozen vials of cells were thawed, cultured and expanded to reach the desired number, based on the cell provider's instructions. $32 \mathrm{~mm}$ diameter glass coverslips (VWR International, Radnor, PA, USA) were sterilised in $70 \%$ ethanol and rinsed twice with sterile phosphate buffer saline (PBS) (Gibco ${ }^{\circledR}$, Gaithersburg, MD, USA) and placed in in 6-well cell culture plates (TPP, Trasadingen, Switzerland) prior the seeding day. Cells of passage 6 were seeded on the glass coverslip at a density of $9 \times 10^{4}$ cells/well, in a cell growth medium consisting of Dulbecco's Modified Eagle Medium (DMEM) high glucose $+10 \%$ Fetal Calf Serum (FCS) and 1\% Penicillin/Streptomycin (10.000U/ml) all obtained from (Sigma-Aldrich, Hamburg, Germany), placed in a humidified incubator at $37^{\circ} \mathrm{C}, 5 \% \mathrm{CO}^{2}$. The culture medium was changed initially, one day after seeding and then twice weekly. Electrical stimulation was applied using the described device (Mobini et al., 2016). Half of the samples in control group were exposed to $10^{-8} \mathrm{M}$ Dexamethasone, $10 \mathrm{mM} \beta$-glycerophosphate, and $0.2 \mathrm{mM}$ Ascorbicacid-2phosphate (Sigma-Aldrich, Germany), to chemically induce osteogenic differentiation. The cells of the experimental groups were exposed to $100 \mathrm{mV} / \mathrm{mm}$ of DC ES for 1 hour per day for 1, 2, 3 and 7 days. All evaluations and assays were performed immediately after last exposure to the electrical field. Cells were fixed in formaldehyde 10\%, permeabilised with Triton-X100, stained with $100 \mu \mathrm{l}$ Phalloidin solution $/ \mathrm{cm}^{2}$ and carefully mounted with Prolong $\circledR$ Gold Antifade Mountant with DAPI (Thermo Fisher Scientific Inc, MA, USA) and viewed using fluorescence light microscopy (Nikon Eclipse 50i, equipped with Lucia GF -DXM1200 version 4.82- imaging software). Individual cell orientation (relative angle to the electrical field, Figure $1 \mathrm{C}$ ) and actin filament orientation of each image, captured from different locations (Anode, Centre and Cathode), 
Figure $1 \mathrm{~B}$, were analysed using CellProfiler, version 2.1.1, (The Broad Institute, MA, USA, available from: www.cellprofiler.org). Description of the pipelines is provided in the supplementary document. To visualize the complied data from the CellProfiler software, a custom-made application in the C\# programming language was used.

\section{Results and Discussions}

Simulation results show that the average electric field strength on the whole cell culture surface was $85 \mathrm{mV} / \mathrm{mm}$. In the anode, cathode and center areas, the average electric field strength was 110,110 and $83 \mathrm{mV} / \mathrm{mm}$, respectively. On the cell culture area, the electric field distributed more evenly between the electrodes with increasing electric field strength around the electrodes. In the peripheral areas parallel to electric field direction, the electric field strength diminished towards the edge. In the peripheral areas perpendicular to electric field direction, the electric field strength was suggestively smaller to average values as seen in Figure $1 \mathrm{~A}$. There was no long term change in $\mathrm{pH}$ or temperature and these have been measured (data not shown).

More than 50 images of different regions, close to either the anode, the center or the cathode areas, were analyzed in different conditions and area of the cell culture well plate, to define the configuration of the cell orientation and actin filaments in each sample. While orientation and cytoskeleton of the cells has been changed significantly in the vicinity of the cathode area, changes were not distinguishable in the center and not detectable in the vicinity of the anode area. Figure 2 demonstrate hMSCs cytoskeleton texture, in the vicinity of the cathode area at day three. In these microscopic images, cells appear to show denser f-actin texture in electrically stimulated group when compared to the cells with no electrical stimulation. The cytoskeleton of the electrically stimulated cells is similar to those, which are not electrically stimulated, but were exposed to the osteogenic supplemented medium. Similarities in the cell response to the electrical and chemical stress, implies that both stress sources could trigger the same pathways in the cells. Differentiation can be estimated by morphological changes in cell cytoskeleton. It is reported that rearrangement 
of the actin bundles into dens actin fibre networks is considered as a singe of differentiation(Treiser et al., 2010).

Figure 3 A displays the outline of the cells in different conditions at day 7 . Figures $3 \mathrm{~B}$ and $\mathrm{C}$ demonstrate the florescent images of the same cells at $10 \mathrm{X}$ and 60X magnification, respectively. These results only referred to the cells in the vicinity of the cathode area, since the most discriminated response of the cells have been observed in the cathode region rather than center and anode area. This could be explained according to the specific chemical environment near the cathode, due to attraction of the positively charged ions such as calcium. Calcium ion flux across the membrane is assumed to trigger various intercellular signalling pathways (Titushkin \& Cho, 2009). Onuma et al. showed that cell shape and orientation changes have been linked to the calciumdependant processes by observations on cytoskeleton redistribution in response to stimulus with or without calcium channel blockers and calmodulin antagonists (Onuma \& Hui, 1988). Additionally, Sun et al. showed that $\mathrm{Ca}^{2+}$ oscillation has been directly linked with hMSCs' differentiation stage (Sun et al., 2006). This $\mathrm{Ca}^{2+}$ oscillation profile can be imminently changed by application of the electrical stimulation. Although the distinct chemical environment near the cathode could be the main reason to get the majority of the responses near the cathode, the higher voltage drop due to increased length of unit along the electrical field could be the reason why we cannot see the same effect in the center of the cell culture area (Tandon et al., 2009). Based on the temporal experiments we also speculated that more confluent cultures are more likely to be affected by electrical stimulation.

Figure $3 \mathrm{D}$, are colour-magnitude graphs, demonstrating the cell orientation in the vicinity of the cathode at day 7 . These graphs were created using $\mathrm{C \#}$ coding, to correlate the percentage of the cells to their specific angle $(\theta)$ relevant to the electrical field (orientation), Figure 1 C. $\theta$ was calculated for each cell (at least 70 cells per image), from the microscopic images, by CellProfiler software and visualized at each condition using the customized coding. The results show that the cells reoriented parallel the electrodes, which means cells aligned perpendicular to the electrical field. Robison mentioned the perpendicular alignment of the muscle cells in response to the DC electrical 
field was interesting as it produces an approximation of the geometrical relationship between neuritis and muscle that occurs in vivo (Robinson, 1985). Cooper and Keller also have observed that the perpendicular alignment is a result of the cells attempt to minimize the perturbing effect of the field on the membrane potential (McCaig et al., 2009). Schmidt and co-workers, showed the alignment of human dermal fibroblast is enhanced by a DC current (Hardy et al., 2015). We also observed cell alignment results are quite similar to the distribution of actin filament orientation, in the same condition. Figure $3 \mathrm{E}$, shows another set of color-magnitude graphs, created in same way as the figure $3 \mathrm{D}$, to visualize actin filaments orientation. Similarities between two set of graphs (cytoskeleton and the cell orientation) suggests orientation of the cells directly linked to the actin cytoskeleton reorganization (Titushkin \& Cho, 2007). It is also shown that depolymerisation of the actin cytoskeleton induces nuclear trafficking of regulatory proteins and global effects on gene transcription. The continued presence of intra-nuclear actin, which forms rod-like structures that stain with phalloidin, is associated with induction of robust expression of the osteogenic genes leads to acquisition of osteogenic phenotype (Sen et al., 2015).

\section{Conclusion}

In conclusion, human mesenchymal stem cells react to the $100 \mathrm{mV} / \mathrm{mm} \mathrm{DC}$ electrical field. This response is quite evident in cell and cytoskeleton reorientation perpendicular to the electrical field in the vicinity of the cathode area. In addition, the changes in the texture of actin filaments are comparable to the changes forced by chemical stress. In this study, the chemical stress applied by osteogenic differentiation ingredients. The results of this study may help our understanding of the mechanism underlying this phenomenon, which could give a clue to optimization of osteogenic differentiation using electrical stimulation for tissue engineering applications.

\section{Acknowledgment}

BBSRC BB/M013545/ grant financially supports this study. We would like to than Dr Louise Carney, Ms Marie O'brien and Mr Kasama Srirussamee for their assistance with imaging and cell culture experiments. 


\section{References}

Balint, R., Cassidy, N. J., Hidalgo-Bastida, L. A., \& Cartmell, S. (2013). Electrical Stimulation Enhanced Mesenchymal Stem Cell Gene Expression for Orthopaedic Tissue Repair. Journal of Biomaterials and Tissue Engineering, 3(2), 212-221. doi: 10.1166/jbt.2013.1081

Grayson, W. L., Martens, T. P., Eng, G. M., Radisic, M., \& Vunjak-Novakovic, G. (2009). Biomimetic approach to tissue engineering. Semin Cell Dev Biol, 20(6), 665-673. doi: 10.1016/j.semcdb.2008.12.008

Griffin, M., \& Bayat, A. (2011). Electrical stimulation in bone healing: critical analysis by evaluating levels of evidence. Eplasty, 11, e34.

Hammerick, K. E., Longaker, M. T., \& Prinz, F. B. (2010). In vitro effects of direct current electric fields on adipose-derived stromal cells. Biochemical and Biophysical Research Communications, 397(1), 12-17. doi: 10.1016/j.bbrc.2010.05.003

Hardy, J. G., Li, H., Chow, J. K., Geissler, S. A., McElroy, A. B., Nguy, L., . . Schmidt, C. E. (2015). Conducting polymer-based multilayer films for instructive biomaterial coatings. Future Sci OA, 1(4), FSO79. doi: 10.4155/fso.15.79

Kim, I. S., Song, J. K., Zhang, Y. L., Lee, T. H., Cho, T. H., Song, Y. M., . . Hwang, S. J. (2006). Biphasic electric current stimulates proliferation and induces VEGF production in osteoblasts. Biochim Biophys Acta, 1763(9), 907-916. doi: 10.1016/j.bbamcr.2006.06.007

Levin, M. (2009). Bioelectric mechanisms in regeneration: Unique aspects and future perspectives. Semin Cell Dev Biol, 20(5), 543-556. doi: 10.1016/j.semcdb.2009.04.013

McCaig, C. D., Song, B., \& Rajnicek, A. M. (2009). Electrical dimensions in cell science. J Cell Sci, 122(Pt 23), 4267-4276. doi: 10.1242/jcs.023564

Mobini, S., Leppik, L., \& Barker, J. H. (2016). Direct current electrical stimulation chamber for treating cells in vitro. Biotechniques, 60(2), 95-98. doi: $10.2144 / 000114382$

Nuccitelli, R. (2003). Endogenous electric fields in embryos during development, regeneration and wound healing. Radiat Prot Dosimetry, 106(4), 375-383.

Onuma, E. K., \& Hui, S. W. (1988). Electric-Field Directed Cell-Shape Changes, Displacement, and Cytoskeletal Reorganization Are Calcium Dependent. Journal of Cell Biology, 106(6), 2067-2075. doi: DOI 10.1083/jcb.106.6.2067 
Robinson, K. R. (1985). The Responses of Cells to Electrical Fields - a Review. Journal of Cell Biology, 101(6), 2023-2027. doi: DOI 10.1083/jcb.101.6.2023

Sen, B., Xie, Z. H., Uzer, G., Thompson, W. R., Styner, M., Wu, X., \& Rubin, J. (2015). Intranuclear Actin Regulates Osteogenesis. Stem Cells, 33(10), 3065-3076. doi: 10.1002/stem.2090

Sun, S., Titushkin, I., \& Cho, M. (2006). Regulation of mesenchymal stem cell adhesion and orientation in 3D collagen scaffold by electrical stimulus. Bioelectrochemistry, 69(2), 133-141. doi: 10.1016/j.bioelechem.2005.11.007

Tandon, N., Goh, B., Marsano, A., Chao, P. H. G., Montouri-Sorrentino, C., Gimble, J., \& Vunjak-Novakovic, G. (2009). Alignment and Elongation of Human AdiposeDerived Stem Cells in Response to Direct-Current Electrical Stimulation. 2009 Annual International Conference of the leee Engineering in Medicine and Biology Society, Vols 1-20, 6517-6521. doi: Doi 10.1109/lembs.2009.5333142

Titushkin, I., \& Cho, M. (2007). Modulation of cellular mechanics during osteogenic differentiation of human mesenchymal stem cells. Biophysical Journal, 93(10), 3693-3702. doi: 10.1529/biophysj.107.107797

Titushkin, I., \& Cho, M. (2009). Regulation of Cell Cytoskeleton and Membrane Mechanics by Electric Field: Role of Linker Proteins. Biophysical Journal, 96(2), 717-728. doi: 10.1016/j.bpj.2008.09.035

Treiser, M. D., Yang, E. H., Gordonov, S., Cohen, D. M., Androulakis, I. P., Kohn, J., . . Moghe, P. V. (2010). Cytoskeleton-based forecasting of stem cell lineage fates. Proceedings of the National Academy of Sciences of the United States of America, 107(2), 610-615. doi: 10.1073/pnas.0909597107 


\section{Figures:}
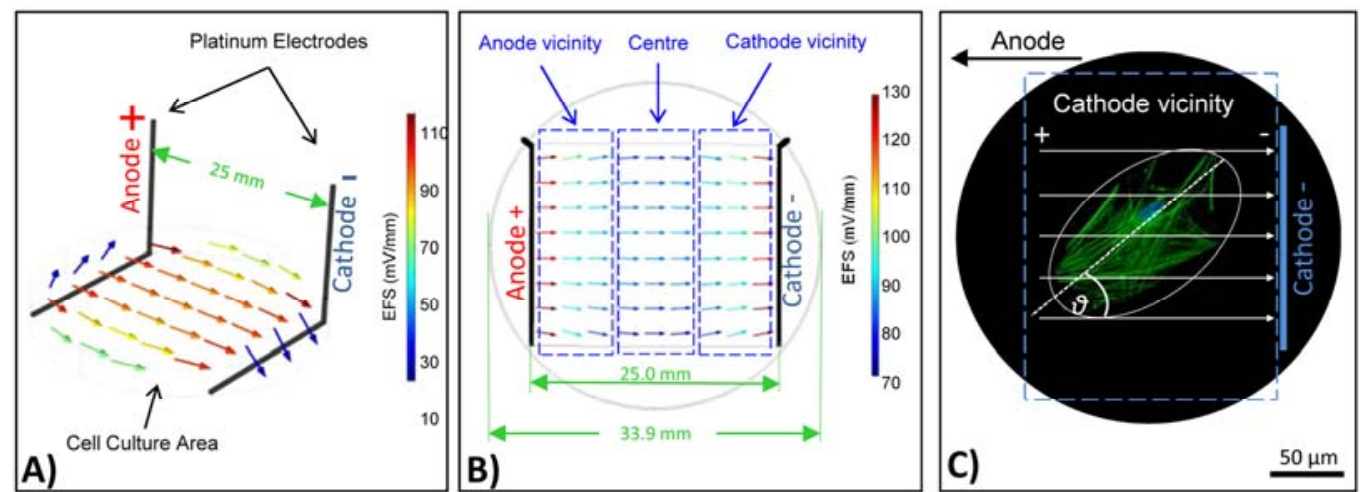

Figure 1. Computational modeling and simulation analysis. A)

Computational model of the electro-bioreactor and simulation of the electrical field within the cell culture area, B) Electrical field strength distribution in the anode, center and the cathode area of the cell culture well. C) The $(\theta)$ angle of the cells relevant to the electrical field, which is measured by the CellProfile software to determine the orientation.

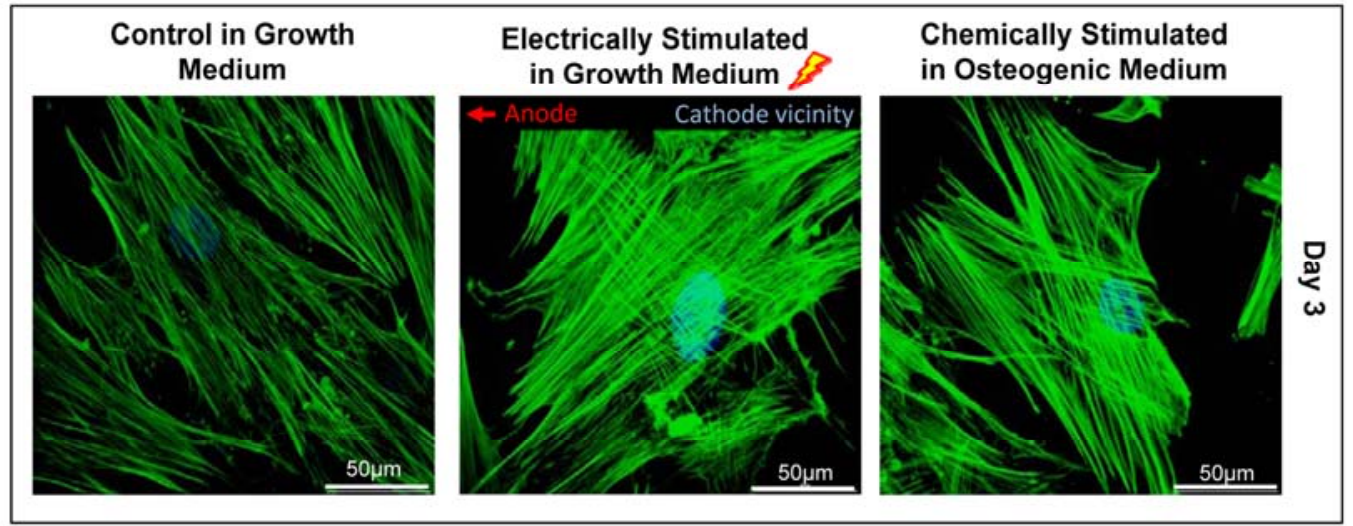

Figure 2. Cell profile analysis at day 3 in the vicinity of the cathode area. Immunofluorescence images of the cytoskeleton (F-actin) and nuclei of human mesenchymal stem cells (60X), in different conditions; Non-electrically stimulated in growth medium (control group), electrically stimulated in growth medium (electrically stimulated group) and non-electrically stimulated in osteogenic induced medium (chemically stimulated group). 


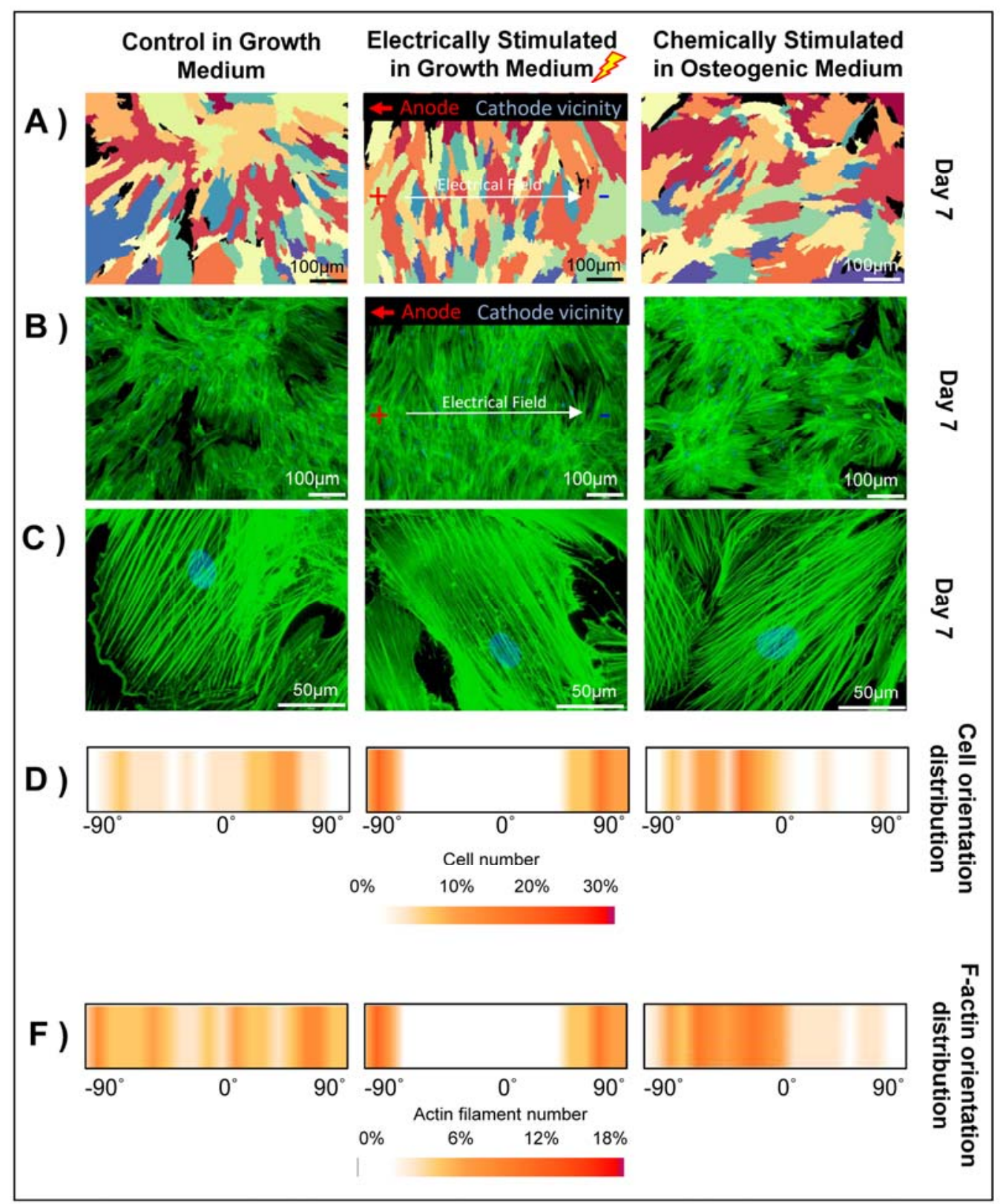

Figure 3. Cell profile analysis at day 7 in the vicinity of the cathode area.

A) CellProfiler analysis of the cell outlines based on the intensity and orientation of the cytoskeleton and distance from the nucleus. B) Immunofluorescence images of the cytoskeleton (F-actin) and nuclei of the human mesenchymal stem cells (10X), C) (60X). D) Distribution of the cell orientation, and E) actin filament orientation. All experiments assessed in three different conditions; Non-electrically stimulated in growth medium (control group), electrically stimulated in growth medium (electrically stimulated group) and non-electrically stimulated in osteogenic induced medium (chemically stimulated group). 